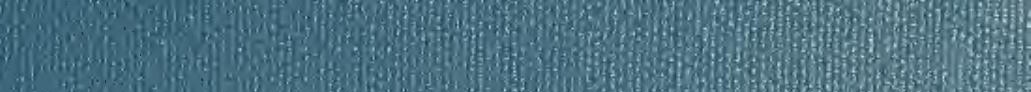
(1) (20.6. (1) (1) 20 Hon (1) ; (5)

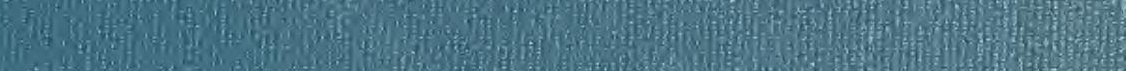
10.6.

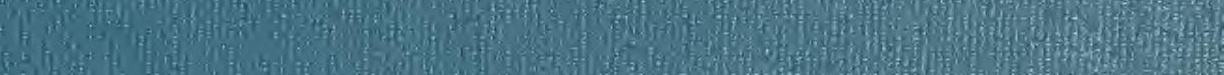
(5) (1)

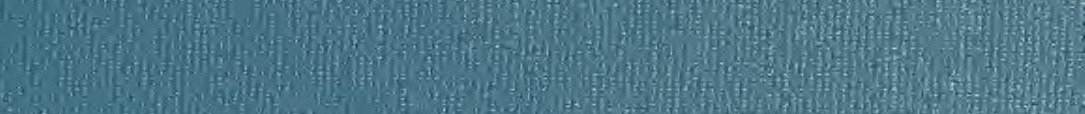

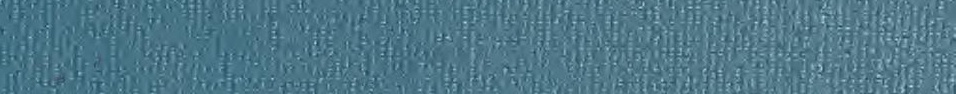
ar 7 ing (19.5

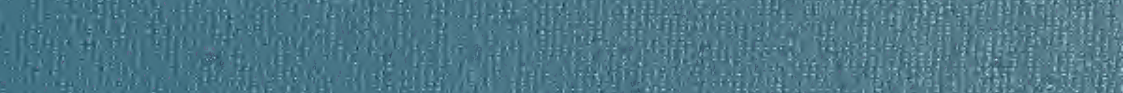

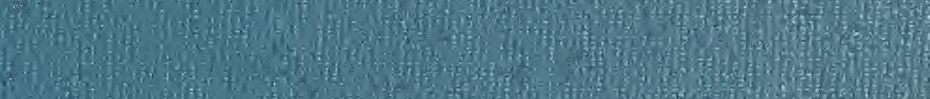
H.

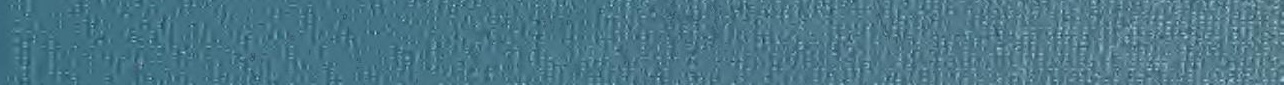
(1) (1) 19. Ho 6.t.

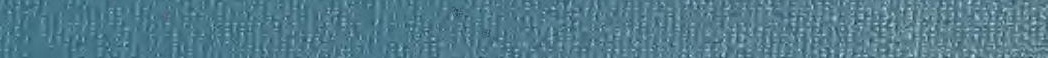
Q: 6. A (12.6. (1) (2. 8. ato 

Digitized by the Internet Archive in 2011 with funding from

LYRASIS members and Sloan Foundation 



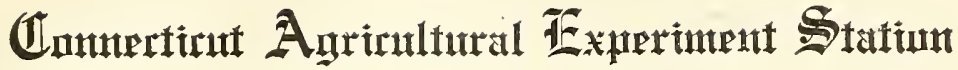

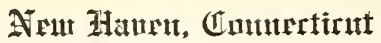

\section{Perithecia of Thielavia basicola Zopf in Culture} And The Stimulation of their Production by Extracts from other Fungi

\section{BOTANICAL DEPARTMENT}




\section{OFFICERS AND STAFF}

August, 1925.

\section{BOARD OF CONTROL.}

His Excellency, John H. Trumbull, ex-officio, President.

Charles R. Treat, Vice-President. . . . . . . . . . . Orange

George A. Hopson, Secretary. . . . . . . . . . . . . . Mount Carmel Wm. L. Slate, Jr., Director and Treasurer............. New Haven

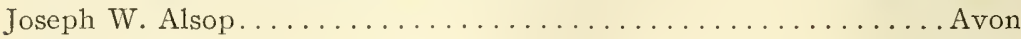

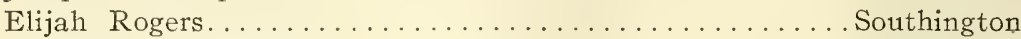

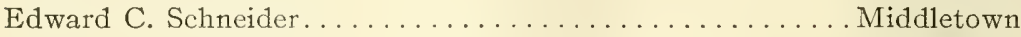

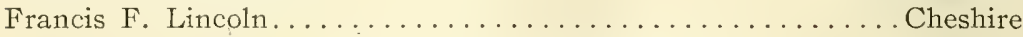

STAFF.

E. H. Jenkins, PH.D., Director Emeritus.

Administration. WM. L. Slate, JR., B.Sc., Director and Treasurer.

Miss L. M. BRAUtLECHT, Bookkeeper and Librarian.

Miss J. V. Berger, Stenographer and Bookkeeper.

Miss MARY BRADley, Secretary.

G. E. GRAHAM, In Charge of Buildings and Grounds.

Chemistry:

Analytical

Laboratory.

Biochemical

Laboratory.

Botany.

Entomology.

Forestry.

Plant Breeding.

Soil Research.

Tobaco Sub-station at Windsor.
E. M. Bailey, Ph.D., Chemist in Charge.

R. E. ANDREW, M.A.

C. E. SHEPARD

OWEN L. NOLAN

HARRY J. Fisher, A.B.

W. T. MATHIS

Frank C. Sheldon, Laboratory Assistant.

V. L. Chur Chill, Sampling Agent.

Miss MaBel Bacon, Stenographer.

T. B. Osborne, Ph.D., Sc.D., Chemist in Charge.

G. P. Clinton, Sc.D., Bolanist in Charge.

E. M. STOdDard, B.S., Pomologist.

Miss Florence A. MCCORMick, PH.D., Pathologist.

Willis R. Hunt, Ph.D., Scientific Assistant

A. D. McDonnell, General Assistant.

MrS. W. W. KeLSEY, Secretary.

W. E. Britton, Ph. D., Entomologist in Charge; Stale Entomologist B. H. WALDEN, B.AGR.

M. P. ZAPPE, B.S.

Philip Garman, Ph.D.

Roger B. Friend, B.SC., Graduate Assistant.

JoHN T. Asmworth, Deputy in Charge of Gipsy Moth Work.

R. C. Botsford, Depuly in Charge of Mosquito Elimination.

Miss Gladys M. Finley, Stenographer.

WALter O. Filley, Forester in Charge.

H. W. Hiсоск, M.F., Assistant Forester.

Miss Pauline A. Merchant, Stenographer.

DONald F. Jones, S. D., Geneticist in Charge.

P. C. MangelsdorF, S.D., A ssistant Geneticist.

M. F. Morgan, M.S., Investigator

George D. Scarseth, B.S., Graduate Assistant.

P. J. Anderson, Ph.D., Pathologist in Charge.

N. T. Nelson, PH.D., Plant Physiologist. 


\title{
Perithecia of Thielavia basicola Zopf in Culture and the Stimulation of their Production by Extracts from other Fungi.
}

\author{
By
}

\section{Florence A. McCormick.}

During a disease survey of tobacco in the summer of 1920 , Thielavia basicola Zopf was found to be unusually abundant, the heavy rains in the early part of the season favoring its development. Perithecia were plentiful and, in some cases, they were found to be deeply embedded in the tissues of the host. It, therefore, seemed worth while to attempt to establish more definitely the connection of the ascospore stage with the chlamydospores and endoconidia, all three spore forms being known by the name Thielavia basicola Zopf, since Peglion, in 1900, (19) has given the only published record of perithecia in artificial culture. Aside from its scientific interest, it is of economic value to know whether there are two fungi or only one, possessing all spore forms, parasitic on its agricultural hosts. Thielavia basicola Zopf is a well known parasite, chiefly serious on tobacco, the violet and many of the Leguminosae. Johnson mentions thirty-nine hosts compiled by previous investigators and gives sixty-six additional ones.

\section{HistoricAL.}

The literature cited below concerns, in the main, the perithecia commonly assumed to be the perfect stage of the fungus producing chlamydospores and endoconidia known as Thielavia basicola Zopf and is only a small part of the mass of publications bearing chiefly on the economic problems connected with that fungus.

In 1850 Berkeley and Broome (2) found the chlamydospores at the base of stems of peas and Nemophila auriculata and gave the fungus the name of Tormla basicola n. s. In $1876 \mathrm{Zopf}$ (33) published an article in which he described a fungus growing on Senecio elegans L. in the Botanical Garden of Berlin and he recognized the chlamydospores as identical with those described and figured by Berkeley and Broome. In addition to the chlamydospores, he described endoconidia, ascospores and spermatia. The last spore form has not been observed by other workers and Zopf himself omitted it from a later publication. Due to the association of perithecia with the chlamydospores and endoconidia, Zopf, in his publication of 1876 , changed the name, Torula basicola, given by Berkeley and Broome, to Thielavia basicola and placed the fungus in the Perisporiaceae. Since the date of that publication the fungus bearing chlamydospores and endoconidia, noted above, has also been known as Thielavia basicola Zopf and the perithecia 
occasionally found with them have been considered the perfect stage of that fungus. In August, 1876, Sorokin (30) announced the finding of a new fungus on the roots of Cochlearia armoracia. He described the chlamydospores, but, not recognizing them as belonging to the fungus found by Berkeley and Broome twenty-six years before, nor knowing of Zopf's discovery, named the fungus Helminthosporium fragile sp. $\mathrm{n}$. Saccardo lists the fungus in three different places and under as many different names. He retains the name for the chlamydospore stage given by Berkeley and Broome (23), but he changed the name Helminthosporium fragile Sorok., given by Sorokin, to Clasterosporium fragile (Sorok.) Sacc. (24). He also gives a description of Thielavia basicola Zopf (22), including in it perithecia along with the other spore forms.

In his paper of 1891, Zopf (34) gives a detailed account of a new disease of lupines which he found to be due to Thielavia basicola. He did not make cultures but, since perithecia were again found associated with chlamydospores and endoconidia, he still considered the fungus undoubtedly an ascomycete and retained the name Thielavia basicola. This opinion has been generally accepted although the relationship of perithecia to endoconidia and chlamydospores has not been considered completely established, since perithecia are not obtained in artificial cultures and only infrequently found in nature. In classification of fungi, however, Thielavia basicola Zopf is invariably placed with the ascomycetes, on the supposition that chlamydospores, endoconidia and perithecia belong to the same fungus, and taxonomists agree that it is closely related to the Aspergillaceae.

Previous to the report from this Station in 1921(14), Peglion (19) is the only person who had obtained perithecia in a culture. $\mathrm{He}$ found perithecia only once, these occurring after he moistened a three year old culture on potato plugs with a $6 \%$ tartaric acid solution. A week later he discovered that perithecia had developed. Prof. Thaxter, 1891, (31), who found this fungus on violet roots and who was the first to report its presence in America, did not find perithecia and he has never been fully convinced of their relationship to the other two spore forms. Sorauer (29), 1895, does not question the relationship. Oudemans (18) considers Thielavia basicola Zopf as belonging to the Perisporiaceae and he illustrates only a mature perithecium, a mature ascus and a young ascogonium, omitting any reference to the asexual spores. CappellutiAltomare (4) found perithecia associated with chlamydospores on tobacco roots. Aderhold (1) failed to obtain perithecia in his cultures and did not find them in plants infected with that fungus. In discussing perithecia Clinton, 1906, (5) says, "So far as our own observations go we could not positively assert their relationship to the other spore forms of the root rot fungus, but from their presence and the observations of others there seems to be no reason for doubting this relationship." In his report of the following year 
Dr. Clinton (6) further says "During the past year and a half the fungus has been under observation in cultures with various media in an attempt to develop the ascospore stage. This has not been obtained, though the fungus was grown on tobacco roots on which this stage occurs in nature in Connecticut. Fresh tobacco roots containing the fungus were sent to Professor Thaxter, who tried to isolate the ascospores by the Barber method and obtain cultures directly from them-our cultures having come originally from the endospores, or possibly from the chlamydospores-but he was not successful in obtaining such cultures. Professor Thaxter has, on the other hand, a culture of another species of Thielavia which forms ascospores, but never the endospores and chlamydospores. These facts possibly may indicate that the ascospore stage has no relationship to our fungus, and that it occurs on the tobacco roots as a parasite of the fungus rather than as a stage of it." Duggar(8) says, "The association of the ascosporous stage with the others and the apparent continuity of mycelium are believed to show genetic connection." Gilbert (12) also accepts this hypothesis and states that he was fortunate to obtain a perithecium attached to the same hypha which bore an endoconidiophore, but that he never saw an ascus. Foex (10) and Reddick (21) found violets infected with Thielavia basicola Zopf and accepted the relationship of perithecia with the other spore forms. Johnson (15) considers association of the perithecia with chlamydospores in nature as an evidence of their relationship. Peters (20), who did not obtain perithecia in his cultures and only once found them in his investigations in the field, questions their connection with the chlamydospores and endoconidia.

Ferraris (9) distinguishes the asexual stage from the ascospore stage, applying the name Thielaviopsis basicola (Berk.) Ferraris to the fungus which bears the chlamydospores and endoconidia and the name Thielavia basicola Zopf to the ascospore stage, not, however, implying two distinct fungi. To simplify the nomenclature in this paper the writer is following hereafter the terminology of Ferraris for these different stages.

\section{Experiments With a Conidum-Chlamydospore Culture.}

In August, 1920, a culture of Thielaviopsis basicola (Berk.) Ferraris, culture No. 396, was isolated from tobacco roots in which there were large numbers of perithecia associated with chlamydospores. Pieces of the infected roots were thoroughly washed in running water, followed by sterilized water, and put on oat agar containing some tobacco leaf extract. An endoconidium-chlamydospore culture was obtained, but no perithecia were produced.

Peglion's result indicated that nutrition might be a factor in the development of perithecia. Repeated efforts were made, therefore, to induce the formation of perithecia by the use of various kinds of media, by the provision of an excess of food, by 
slow starvation and, finally, by partial starvation followed by an abundance of food.

It was thought that tobacco extract might be a favorable food, and agar was made with it, alone and in combination with other substances. Sterilized tobacco seedlings were used alone and made up with agar and soil. Stock agars were made with ground peas, beans, oats, corn, peanuts, carrots, potatoes and beef extract. These media were used alone and also in combination with other nutrients, such as glucose and yeast, and a series of cultures, grading from slightly acid to slightly alkaline, was also tried. Plugs of carrot, potato, pineapple and pea pods gave an excellent growth of the fungus, but orange and lemon plugs gave little or no growth. Transfers from luxuriant cultures to water agar were made, with the hope that a change from an abundance of food to a negligible quantity might be effective, and transfers were also made from one highly nutritive medium to another equally so, but of a different kind. With some cultures gelatine was substituted for agar. The results of these tests were strictly negative, not a single culture showed a development of perithecia. Eighteen cultures on various media in protected test tubes, were planted outdoors in the spring and were left throughout the summer to see if the natural temperature of the soil might be a factor. Here again the results were entirely negative.

\section{Perithecia in Culture.}

In view of the negative results of the nutrition experiments it seemed worth while to determine whether or not perithecia of Thielavia basicola Zopf were the product of sexual strains. It was the intention of the writer to secure during the summer of 1921 as large a number of strains as possible for the purpose of making mixed cultures, but work on tobacco wildfire prevented making such collections. No other culture in addition to culture 396 was procured until later in the summer when some violet plants, heavily infected with chlamydospores of Thielaviopsis basicola (Berk.) Ferraris and perithecia of Thielavia basicola Zopf, were sent to Dr. Clinton from a greenhouse near Hartford. The writer visited the greenhouse and secured fresh material for culturing.

On August 9th pieces of these roots were cultured like the tobacco roots from which culture 396 was obtained, put into four Petri dishes and given the culture number 1351. On August 15th a slight growth of Thielaviopsis basicola was perceptible and transfers were made to three tubes of pea meal agar and three tubes of carrot agar. Two days later additional transfers were made to seven tubes of carrot agar. Nothing further was done with these cultures until October 6th. On that date one of the transfers made on pea meal agar, August 15th, showed chlamydo- 
spores, endoconidia and perithecia. This tube was so contaminated with bacteria that, although sixteen transfers to tubes and two to Petri dishes were made, only a feeble growth was obtained. Subsequent transfers failed to restore it and the culture was finally lost. Of the seven transfers made on carrot agar, August 17th, one showed perithecia as well as chlamydospores and endoconidia and the remaining six had only chlamdospores and endoconidia. The growth of these six cultures was feeble on account of bacterial contamination and they, too, were finally lost. The culture containing perithecia along with the two asexual spores was also contaminated with bacteria and a fungus, still undetermined, but repeated culturing freed it from bacteria and later from the fungus.

There can be no doubt that culture 1351, obtained from the violet, is the fungus commonly known as Thielavia basicola Zopf. As stated above, Professor Thaxter (31), in 1891, announced the finding of this fungus on violets in Connecticut. In regard to perithecia he makes the following statement: "Zopf describes an ascosporic condition on which the genus Thielavia is founded, which has not been observed by the writer except as a parasite on other fungi (species of Isaria)." Foex (10) also found Thielavia basicola on violets and he gives a description of the disease and figures chlamydospores and perithecia with ascospores. In regard to the relationship of perithecia with the other spore forms he says: "Tontefois, il est hors de doute, après les observations de Zopf, que ces conceptacles appartiement bien au champignon qui constitue des endoconidies et des chlamydospores." In his paper on violet diseases Reddick (21) says: "The ascosporic stage, mentioned above, does not seem to play a particularly important role in the life cycle of this organism. If it were commonly developed it would seem reasonably certain that the numerous workers in this country and abroad would have seen and recorded its occurrence more frequently." Reddick's illustrations of infected violet plants agree well with Fig. 1, Plate XXXVII. The plants were considerably stunted and had comparatively small, yellowish leaves. In some cases the root system was almost entirely decayed, only a few lateral roots remained and the cortex of the main root was almost disintegrated, in places exposing the network of xylem.

Sections of some diseased violet roots, collected from the greenhouse mentioned above, showed numerous chlamydospores borne internally in the cortex as well as in the xylem, medullary rays and pith. Fig. 3, PI. XXXVII, taken from such a root, also shows sclerotial masses of mycelium completely filling some of the cells. The chlamydospores shown in this figure are identical with those found in tobacco. Endoconidia from the violet are also like those in the culture isolated from the second host. In addition to Brierley's description (3) of endoconidia, Gilbert (12) has also described both spore forms and it is not necessary to repeat them here. 
Perithecia, however, are not so well known. Some features noted by previous observers may here be re-emphasized and additional ones given. Perithecia have been found by the writer in roots of tobacco (P1. XXXVII, Fig. 6), the pea (P1. XXXVII, Fig. 5), the violet (P1. XXXVII, Figs. 2 and 4 ) and recently of Antirrhinum. Sections have been made of the first three infected roots mentioned and the perithecia found in their tissues are alike in all. They are found chiefly in the cortex, but they are also located on the surface lying among masses of chlamydospores and no tissue of the root is entirely free from their invasion. The description of them as seen in culture, however, applies only to those isolated from the violet as no culture of them has been secured from any other host. In culture the perithecia of Thielavia basicola Zopf are globular or nearly so, but in nature the pressure of the surrounding cells of the host may make them some what elongated, one dimension occasionally being nearly twice as great as the other. The cells of the tightly twisted and intertwined hyphae, composing the enveloping sheath, vary in size so as to make the perithecium "rough" as Gilbert described it. The enveloping sheath is hyaline or slightly tinted. At maturity the perithecium looks black which is due to the very dark brown color of the ascospores lying within. There is no sign of an opening of any kind so that it may be considered a true cleistocarp. The asci are exceedingly fragile and by the time the ascospores are mature they have disintegrated leaving the ascospores free in the perithecial cavity. Asci, however, can be seen and obtained intact by gently pressing the cover glass over a nearly mature perithecium. If the ascospores are mature the ascus will invariably be ruptured. The asci are hyaline, nearly egg-shaped and contain eight ascospores. (P1. XXXVIII, Fig. 23.)

The size of the perithecium has been commonly given as 80 to $100 \mu$. The writer has found this size rather large. In the sections of the tobacco and pea roots the perithecia measure about the same, the maximum size of those measured in tobacco being $72 \mu$ and those of the pea $66 \mu$. In the violet roots the perithecia were somewhat larger, the maximum dimension reaching as high as $99 \mu$ which, however, is exceptional even in this host. The larger size of the perithecia in the violet roots may possibly be due to greenhouse conditions. In culture, perithecia, which it is recalled were isolated from the violet, average about the same in size as those found in tobacco and pea roots.

The ascospores are small, dark brown and lenticular with one end blunt, from which germination occurs. In mass they appear black. The relatively large oil drop is the conspicuous feature of the cell contents. In the roots of the violet, tobacco and pea, as well as those in culture 1351, the general size is 10 to $13 \mu$ by 4.5 to $6.5 \mu$.

The ascogonium begins as a small lateral branch attached at right angles to the main hypha. The early stages, in gross appear- 
ance, apparently do not differ essentially from the figures given by Fraser and Chambers (11) for Aspergillus herbariorum and by Dale (7) for Aspergillus repens de Bary, although loose coils were not observed in this fungus. No attempt has been made to study the nuclear behavior and all the drawings of these stages, given here (P1. XXXVIII, Figs. 11-22) were made from living material. The coil early becomes compact and additional hyphae soon bud out from the primary coil, thereby concealing it. The entire process takes place very quickly, as perithecia, apparently mature, can be seen along the sides of the tube eight days after the transfer has been made. Where observed, the early stages gave no indication of more than one hypha being involved in the ascogonial coil.

\section{Possible Factors Inducing the Formation of Perithecia.}

Having obtained perithecia in this accidental way the question arose as to the factors which brought forth their appearance. It was first thought that this might be a specialized form growing on this particular lot of violets. More violets were procured from the same greenhouse and cultures were made from individual plants. Ten additional cultures were isolated from as many different plants, but while all produced endoconidia and chlamydospores, none formed perithecia. If, then, culture 1351 were a unique strain it could not be general throughout the plants in the greenhouse, but one might expect to obtain perithecia from one-spore cultures of its endoconidia and chlamydospores. For the purpose of investigating this point one-endoconidium cultures were made. The spores were plated in stiff agar and the single germinating spores were transferred to tubes.

\section{One-Conidium Cultures.}

Of the 260 one-endoconidium cultures that were isolated from culture 1351 all showed a luxuriant development of endoconidia and chlamydospores, but no perithecia were found in them. This result apparently gave the solution as to the cause of the nonappearance of perithecia in some of the first transfers made from culture 1351. In an attempt to obtain transfers free from bacteria and the associated fungus an effort was made to touch the mycelium very lightly with the needle in order to carry over only endoconidia. For a time it was thought that perithecia were completely lost, but later it was found that transfers which included some of the mycelium always produced perithecia.

In isolating the germinating endoconidia it was noted that they vary somewhat in shape from the elongated narrow type with straight ends to short almost egg-shaped ones. The one-spore cultures were made from as many different types as possible, but the subsequent growth was alike in all.

Although no one-endoconidium cultures developed perithecia 
it seemed possible that culturing two or more together might lead to their production. To facilitate the process of culturing, transfers from several tubes were frequently put into one tube so that while all the 260 cultures were used only 151 mixed cultures were made. In case perithecia developed in a tube containing transfers from more than two tubes the cultures producing them could be readily separated. No perithecia were in any of these tubes.

\section{Chlamydospore Cultures.}

For the same reason chlamydospore cultures were also isolated from culture 1351. They are, however, much more difficult to secure than endoconidium cultures, but by treating them with pepsin good germination was obtained. Pieces of culture, three or four weeks old, were thoroughly washed, since the numerous endoconidia, which are everywhere present in cultures, germinate so rapidly as to easily contaminate the chlamydospore cultures. Chlamydospores cling tenaciously together in chains and frequently more than one chlamydospore in a chain will germinate. In such cases the entire chain was transferred to a tube with the intention of accurately making single spore cultures in case perithecia were found in any of the tubes. Ninety chlamydospore cultures were included in the twenty mixed cultures made, each tube containing transfers from four or five cultures, but in none of these twenty tubes were perithecia produced. It was the intention to make an extensive series of plantings of one-endoconidium cultures with chlamydospore cultures, but investigations with the asco stage made this seem unnecessary and comparatively few were made. In no case did these produce ascospores but both asexual spores.

\section{Investigations with the Ascospore Stage.}

In studying the young stages of the ascogonium an effort was made to ascertain the relation of the ascogonial hypha to the mycelium which bears endoconidia and chlamydospores, since as noted above, culture 1351 is a mixed culture bearing all three spore forms. As the figures of Aspergillus also show, there was no indication here of hyphae from two different mycelia being concerned in the ascogonial coil. With the hope of getting a clearer view of the individual threads and also of being able to get cultures from them, small pieces of mycelium were cultured on clear agar with the idea that possibly an ascogonial hypha might become sufficiently separated so that it could be cut free from contaminating endoconidia, chlamydospores or the mycelium which bears them. All such attempts failed and one-ascospore cultures seemed to be the only method of getting accurate evidence of the relationship of the perithecia to the endoconidia and chlamydospores. 
The Germination of Ascospores. Endoconidia are produced in such numbers that it is also necessary to free perithecia from them in order to procure pure ascopore cultures, for they germinate so readily that they contaminate the smaller and more slowly germinating ascospores. Pieces of culture, containing many perithecia, were thoroughly washed under a strong flow of tap water and finally in sterilized water. It was often necessary to tease away the endoconidia with sterilized needles.

Various methods, recommended for inducing germination of other ascospores, were tried without success. However, in the writer's experience the germination of ascospores of Thielavia basicola is very low, so this may be the cause of the failure. The first germination was obtained in a van Tieghem cell containing a trace of pepsin in the drop of water. All subsequent cultures were made by crushing the washed perithecia in a tube containing beef broth, a trace of pepsin and a minute particle of thymol. A better method, probably, would be to filter the solution containing pepsin through a Berkefeld filter, thus making thymol unnecessary. After about half an hour loops of the broth were transferred to melted beef agar which contained about $3 \%$ agar. A very clear agar is essential on account of the small size of the ascospores. Germination begins to appear in about five days. The open Petri dish was examined under the microscope and germinating ascospores transferred with a sterile needle to a suitable medium, in this case pea meal agar. By this method fortytwo one-ascospore cultures were obtained. The germination of these spores was obtained only when pepsin was used and it was not determined whether or not they will germinate without it. The sole aim was to procure germination and no consideration was given to factors bringing it about. It is quite possible that freezing may be an aid to germination of the ascospores and the age of the spores may also be important. The best germination was secured with spores taken from cultures six weeks or two months old.

As previously stated the ascospore germinates at the blunt end (P1. XXXVIII, Fig. 1) and the writer has not found more than one germ tube connected with a spore. Next to the spore coat, the germ tube has a one-sided bulbous enlargement and variation in diameter with considerable curling is characteristic of the older as well as the younger hyphae (P1. XXXVIII, Figs. 9, 10). Especially in the early stages the cells are practically filled with a fine granular content (P1.XXXVIII, Figs. 1-8). Growth is comparatively slow and although small test tubes were used it was several days before the delicate hyphae could be detected growing up on the sides of the tube and along the edge of the medium. The mycelium is white and on pea meal agar seldom shows the slightest tendency to become cottony, neither does it make a feltlike growth as does Thielaviopsis basicola. The hyphae grow sparsely over the surface and down into the interior of the medium. 
None of the forty-two one-ascospore cultures produced either chlamydospores or endoconidia and although they have been in culture more than two years they have produced only perithecia and these usually developed sparingly and sometimes not at all. While there may be some difference of growth in the media commonly used for fungi, there has never been the least indication of even the rudiments of chlamydospores or endoconidia. Pea meal agar is the stock medium used and, while the growth on it is usually so delicate as to be readily overlooked, it seems to be a satisfactory one for this fungus, as all the forty-two cultures are still in good condition. The fungus also grows well on corn meal, prune, oat, potato, carrot and bean meal agars. However, there is often a difference in growth of cultures made at the same time and on the same agar. The factor, or factors, bringing about this condition have not been ascertained. With the above media in only a few cultures was there any approach to a cottony mycelium and, while the mycelium was abundant, it still remained delicate, being, in comparison with other fungi, verv inconspicuous.

\section{Mixed Cultures of Thielavia Basicola Zopf and Thiela viopsis basicola (Berk.) Ferraris}

The fact that none of the one-ascospore cultures produced either endoconidia or chlamydospores suggested that the ascospore cultures might be sexually related to the endoconidium-chlamydospore strains without, however, producing any asexual spores. With this idea in mind each of three one-ascospore cultures was cultured with eighty-one one-endoconidium cultures, from culture 1351, and with three Thielaviopsis basicola from tobacco, four from violet and one from garden peas. Perithecia were abundantly produced in all. Usually within six days immature perithecia could be detected in the tube placed under the microscope and in eight days almost mature perithecia could be seen with a hand lens. The remaining thirty-nine perithecial cultures were cultured with the eight cultures isolated from tobacco, violet and pea and they were also stimulated to produce an abundance of perithecia.

These results seemed to indicate that production of perithecia in this fungus was due to different sexual strains. However, it was early noted that there was a tendency to form perithecia in the one-ascospore cultures even though they were not cultured with the endoconidium-chlamydospore strains. In such cases perithecia were slower in making their appearance and increased in number as the culture grew older. Furthermore the forty-two cultures varied somewhat in this ability of forming perithecia when cultured alone and there was often a difference in cultures of the same strain made at the same time and on the same medium. In no case, however, did a single culture alone produce perithecia as quickly or as abundantly as when grown with endoconidium- 
chlamydospore cultures. The factors which cause this difference in production of perithecia have not been ascertained. In autoclaves in which steam is in contact with the tubes a little more moisture at times collects in some tubes than in others, so it was thought that possibly the rigidity of the medium might be a factor. Cultures were made on media containing different concentrations of agar, but these gave no definite results, perithecial formation not being increased in any of them. A few cultures on oat agar, made in the usual way, formed a ring of perithecia along the upper edge of the medium, but these were not general throughout the tube and not always obtained. Possibly a slow drying combined with a favorable medium might be a factor. Occasionally transfers taken from an old dried culture make a more luxuriant growth and form more perithecia than those from newer cultures. For the experiments made on the production of perithecia an ascosporic culture, No. 1603, which alone seldom forms perithecia, was used.

\section{Mixed Cultures of Thielavia Basicola Zopf and other FungI.}

The writer is indebted to Prof. Thaxter for the suggestion of culturing Thielavia basicola Zopf with other fungi to see if the reaction with them is similar to that with Thielaviopsis basicola (Berk.) Ferraris.

First of all, however, Thielavia basicola, culture 1603, the strain which alone rarely produces perithecia, was cultured with the remaining forty-one strains of Thielavia basicola, but there was no additional stimulation in growth or perithecial formation. In this respect the results differ from those obtained by Miss Wineland (32) who found that two one-ascospore cultures of Fusarium moniliforme, grown together, stimulate the production of perithecia.

Other fungi were then tried. The same Thielavia basicola culture, No. 1603, was cultured with 120 strains and species, embracing 43 genera, belonging to Phycomycetes, Ascomycetes, Basidiomycetes and Fungi Imperfecti. In all the tests pea meal agar was used and in each case a transfer from one culture of Thielavia basicola was put into a tube with that from one other fungus. Many of the fungi grew so rapidly as to bury the delicate more slowly growing Thielavia basicola and no evidence of its mycelium could be detected, but in others both species survived in the fully mature culture.

As a result of these experiments it was found that Thielavia basicola Zopf produces abundant perithecia when it is cultured with Cladosporium fulvum, Aspergillus umbrosus, a strain of Aspergillus glancus, Eurotium amstelodami and in a less degree with Fusicladium pirinum. In all cases the perithecia produced in these mixed cultures are exactly alike in every respect to those obtained in the original culture isolated from violet and no trace of chlamydospores or endoconidia was found in them. 
It seems probable that if various other media were used or change of cultural conditions tried that other fungi might react in this same way.

It is interesting that results vary with different species of the same genus. While perithecia of Thielavia basicola were abundantly produced when that fungus was cultured with Cladosporium fulvum, isolated from tomato leaf by the writer, three Cladosporium cultures received from Dr. C. L. Shear, two of which were isolated from cranberry and one from blueberry, were unsuccessful. Aspergillus umbrosus, kindly determined by Drs. Charles Thom and Margaret Church, was obtained from peach preserves and Aspergillus glaucus strain and Eurotium amstelodami were received from the same investigators. Eight additional cultures of Aspergillus, received from them and nine others of the same genus, received from Dr. D. H. Linder, as well as one other species from this laboratory, had no effect in stimulating the production of perithecia. Thielaviopsis paradoxa has a striking resemblance to Thielaviopsis basicola, but two cultures received from Dr. J. P. Martin, Honolulu, and one isolated from banana stalk by the writer, were also unsuccessful. Two cultures of Isaria, received from Dr. F. J. Pritchard, had no effect in increasing the number of perithecia.

Results, similar to those given above, are recorded by Heald and Pool (13) who found that Melanospora pampeana responded in the production of perithecia when grown with Fusarium moniliforme, Basisporium gallarum and to a smaller extent with Fusarium culmorum. Their description of a one-ascospore culture of Melanospora pampeana as showing a "scanty scarcely distinguishable, white mycelium" might apply equally as well to the one-ascospore cultures of Thielavia basicola Zopf. However, in their one-ascospore culture or in transplants from it they never found perithecia, while on the other hand the one-ascospore cultures of Thielavia basicola Zopf spasmodically produce some perithecia when grown alone on an ordinary culture medium. In opposition to the results of Heald and Pool the writer so far has not been able to get a response of perithecia of Thielavia basicola on cultures of other fungi that have been heated in the autoclave or boiled in the open for twenty minutes.

Molliard (16), (17) found that Ascobolus produces perithecia when a bacterium is present in the culture and Sartory announced a similar association necessary for the production of ascospores in a yeast (25) and of perithecia in an Aspergillus (26), (27), (28).

'The writer's experiments have been sufficiently repeated to demonstrate that Thielavia basicola Zopf, though possessing to some degree the ability to form perithecia when cultured alone, is greatly stimulated in the production of these structures when cultured in association with Thielaviopsis basicola (Berk.) Ferraris, Cladosporium fulvum, Aspergillus umbrosus, Aspergillus of the glancus group, Eurotium amstelodami and Fusicladimu pirimum. 
Since Thielavia basicola Zopf does not form either the chlamydospores or endoconidia of Thielaviopsis basicola (Berk.) Ferraris, and since perithecial formation is stimualted equally well by other fungi, there seems to be no real justification for considering Thielavia basicola the perfect stage of Thielaviopsis basicola. Although the frequent association of these two fungi in nature and the fact that their relationship has long been accepted in literature make one reluctant to consider them as two distinct species, yet the cultural evidence is a strong argument in favor of such a view.

\section{The Influence of Extracts upon Production of Perithecia.}

The observations made upon the influence of extracts of some fungi upon production of perithecia are recent, but the experiments have been repeated a sufficient number of times to make them seem worthy of being recorded here. Cultures of several fungi were barely covered with water and allowed to stand about twenty-four hours. The liquid was filtered through paper and then through a Berkefeld filter, thus avoiding sterilization by heat; for, as already stated, cultures of the various fungi, which in living condition stimulate the production of perithecia, after heating, no longer have this stimulating effect. In some cases the liquid only was used and in others the mat of mycelium was crushed in a mortar, squeezed through cheese cloth and the juice thus obtained also filtered with the extract. There is some indication that the latter method is the better one, but this point has not been fully determined. All the extracts from fresh fungi, so far tried, have been made with water only and sterilized by passing the liquid through a Berkefeld filter. Cultures of Thielavia basicola Zopf, No. 1603, were made in the usual way upon pea meal agar and some of the extract, prepared as above described, poured into the tube and allowed to flow over the transplant. In every case the fungus from which the extract was made was also grown upon pea meal agar to avoid conflicting results which might arise from the introduction of some other medium. Check cultures on pea meal agar alone were also made in every series.

Nine different extracts of Thielaviopsis basicola (Berk.) Ferraris were made and each one caused a marked stimulation both in growth and perithecial production, in the majority of cases fully equaling in numbers the perithecia formed in mixed cultures of the two living fungi. Following the use of extracts a stimulation in growth is noticeable within a few days, but the formation of perithecia is slower than when two living fungi are cultured together. However, in every series, the checks have no perithecia or only a few scattered ones, while the cultures treated with the extracts have produced them abundantly. The age of the fungus from which the extract is made, amount of water necessary for 
extracting and the optimum length of time required for extraction are probable factors which affect the number and rapidity of perithecial development.

Three different extracts were made from Cladosporium fulvum and one from Aspergillus umbrosus. In all cases these extracts also greatly stimulated growth and perithecial production. As when grown with the living fungi, Thielavia basicola produces no asexual spores when treated with any of the extracts so far used.

The effect of heat upon the extracts was tried both in the autoclave at twenty pounds pressure for twenty minutes and by boiling in the open for twenty minutes. Without exception both methods of heating have so far completely destroyed the stimulating power of the extract. Extracts from Aspergillus of the glaucus gioup, Eurotium amstelodami and Fusicladium pirinum have not yet been tried.

As stated above, Thielaviopsis paradoxa, in living condition, failed to stimulate the production of perithecia and it was also suggested that the failure with many fungi in living condition might be due to the smothering of the more delicate Thielavia basicola. If this is the situation, then, extracts from such luxuriant fungi might act as stimulants even though the living fungus gave no result. While one experiment is not sufficient to be conclusive it may be stated here that an extract made from Thielaviopsis paradoxa also greatly stimulated growth and perithecial formation. The case is the same with Saccharomyces cerevisiae. Cultures of yeast were made on pea meal agar and mixed cultures were made from them and Thielavia basicola. In each case the yeast completely covered the Thielavia basicola transplant before it had time to grow; but two different extracts made from fresh yeast cultures, stimulated growth and perithecial production. The stimulating factor in the yeast extract was also completely destroyed by heating.

To determine whether commercial extracts of fungi contained the stimulating factor, $1 \%, 2 \%, 4 \%$ and $6 \%$ water solutions of Taka-diastase were made and filtered through a Berkefeld filter. Cultures of Thielavia basicola were treated with these by the same method as with the preceding extracts. The resulting growth far surpassed that following the use of any other extract so far used. The mycelium became very abundant and made almost a felt-like growth. Later, perithecia developed. The type of growth following the addition of Taka-diastase differs so markedly from that in any medium or extract which has been tried that it suggests the presence of two factors, one an unusually potent stimulant for growth and another stimulating perithecial formation. See Plate XXXIX.

The nature of the factors in any of the extracts above considered, causing such a striking increase in growth and production of perithecia of Thielavia basicola, is beyond the scope of the problem at hand. The results with the mixed cultures of Thielavia basicola Zopf and of other fungi are an indication that this fungus should 
not be considered the perfect stage of Thielaviopsis basicola (Berk.) Ferraris any more than of the other fungi above noted. The results with extracts, here recorded, are an additional indication that Thielavia basicola is a distinct fungus and they are also an argument against any ideas of heterothallism that may have been connected with it.

Thielavia basicola Zopf has always been found associated with Thielaviopsis basicola (Berk.) Ferraris on the same hosts. Whether or not it is by itself parasitic on these hosts or; as has been suggested by Dr. Clinton, a parasite on Thielaviopsis basicola, is not yet determined. Inoculations of Thielavia basicola have been made on tobacco in the greenhouse as well as in the field without definite results. The biologic relationship of these two forms is not yet clear.

\section{Summary.}

Perithecia of Thielavia basicola Zopf have been secured in artificial culture.

Since the name Thielavia basicola was given by Zopf on account of the presence of perithecia, the fungus secured from their ascospores should be considered Thielavia basicola Zopf. This is the first report of its isolation in artificial culture.

Thielavia basicola Zopf has a tendency to produce perithecia when grown alone, but this is greatly stimulated when the fungus is grown with Thielaviopsis basicola (Berk.) Ferraris with which it is associated in nature.

It has been shown that Thielavia basicola Zopf is also stimulated to produce perithecia when it is grown with Cladosporium fuloum, Aspergillus umbrosus, Aspergillus of the glancus group, Eurotium amstelodami Mangin, and to a certain extent with Fusicladium pirinum.

It has been shown that Thielavia basicola Zopf is likewise stimulated to produce perithecia when it is treated with water extracts obtained from Thielaviopsis basicola (Berk.) Ferraris, Cladosporium fulvum, Aspergillus umbrosus, Thielaviopsis paradoxa, Saccharomyces cerevisiae and also with a water solution of Taka-diastase.

The above evidence indicates that Thielavia basicola Zopf is not the ascospore stage of Thielaviopsis basicola (Berk.) Ferraris although the two forms are commonly associated.

\section{Literature Cited。}

1. Aderhold, R. Impfversucht mit Thielavia basicola Zopf. Arb. Biol. Adt. Land. Fortw. Kaiser1. Gesundh. 4: 463-5. 1905.

2. Berkeley, M. J. and Broome, C. E. Notices of British Fungi. Ann. Mag. Nat. Hist. II, 5: 461. 1850. pl. II, f. 4.

3. Brierley, W. B. The 'Endoconidia' of Thielavia basicola Zopf. Ann. Bot. 29: 483-493. 1915.

4. Cappelluti-Altomare, G. I semenzai del Tabacco e la Thielavia basicola Zopf. R. Inst. Scafati: 137-47. 1902.

5. Clinton, G. P. Report of the Botanist 1906. Conn. Agr. Exp. Sta. Rept. 1906: 342-368. 1907.

6. Clinton, G. P. Report of the Botanist 1907. Conn. Agr. Exp. Sta. Rept. 1907: 363-368. 1908. 
7. Dale, Elizabeth. On the morphology and cytology of Aspergillus repens DeBary. Ann. Mycol. VII: 215-225. 1909.

8. Duggar, B. MI. Fungous Diseases of Plants: 213.1909.

9. Ferraris, T. Hyphales. Soc. Bot. Ital. Flora Ital. Crypt 1: 233. 1912.

10. Foex, Et. Maladie du pied de la violette. Ann. Ecole Nat. Agr. Montpelier, N. S., 10: 165-171. p1. 6. 1910.

11. Fraser, H. C.I. and Chambers, H. S. The Morphology of Aspergillus herbariorum. Ann. Mycol. 5:419-431. 1907.

12. Gilbert, W. W. The root-rot of tobacco caused by Thielavia basicola. U. S. Dept. Agr., Bur. Plant Ind. Bul. 158: 1-48. pls. I-IV. 1909 .

13. Heald, F. D. and Pool, Venus W. The influence of chemical stimulation upon the production of perithecia by Melanospora Pam. peana Speg. Agr. Exp. Sta. Rept. Univ. Neb. 22: 130-132. 1909.

14. Jenkins, E. H. Report of the Director. Conn. Agr. Exp. Sta.: 6. Oct. $31,1921$.

15. Johnson, James. Host Plants of Thielavia basicola. Jour. Agr. Res. 6: $289-300.1916$.

16. Molliard, M. Rôle des bacteries dans la production des peritheces des Ascobolus. Comp. Rend. 136: 899-901. 1903.

17. Molliard, $\mathbf{M}$. Sur une condition qui favorise la production des peritheces chez les Ascobolus. Bull. Soc. Myc. de France XIX: 150-152. 1903.

18. Oudemans, C. A. J. A. Champignons dans Les Pays-Bas. Tab. II. Fig. 1. 1897.

19. Peglion, V. La moria delle piantine nei semenzai. Ricerche intorno ai mezzi di defesa. Staz. Sper. Agr. Ital. 33: 221-237. 1900.

20. Peters, Leo. The biology of Thielavia basicola. Mitteil. aus der Biol. Reichsanst. für Land-und Forstwirtschaft, Heft 21: 63-74. 1921.

21. Reddick, D. Diseases of the Violet. Mass. Hort. Soc. Trans. 1913: 85-102. 1913.

22. Saccardo, P. A. Thielavia basicola Zopf. Sacc. Syll. Fung. I: 39. 1882 .

23. Saccardo, P. A. Torula basicola B. et Br. Sacc. Syll. Fung. 4: 257. 1886.

24. Saccardo, P. A. Clasterosporium fragile (Sorok) Sacc. Sacc. Syll. Fung. 4: 386. 1886.

25. Sartory, A. Sporulation d'une levure sous l'influence d'une bacterie. Compt. Rend. Soc. Biol. 72: 558-560. 1912.

26. Sartory, A. De l'influence d'une bacterie sur la production des peritheces chez un Aspergillus. Compt. Rend. Soc. Biol. 79: 174175. March 4, 1916.

27. Sartory, A. Sporulation by symbiosis in fungi. Compt. Rend. Acad. Sci. 167: 302-305. 1918.

28. Sartory, A. Production of perithecia by an Aspergillus under the influence of a bacterium. Compt. Rend. Soc. Biol. 83: 11131114. 1920.

29. Sorauer, P. Ueber die Wurzelbräune der Cyclamen. Zeitschr. Pflanzenkr. 5: 18-20. 1895.

30. Sorokin, N. Ueber Helminthosporium fragile sp. n. Hedw. 15: 113. 1876.

31. Thaxter, R. Fungus in violet roots. Conn. Agr. Exp. Sta. Rept. 1891: 166-167. 1892.

32. Wineland, Grace $\mathbf{O}$. An ascigerous stage and synonomy for Fusarium moniliforme. Jour. Agr. Res. XXVIII: 909-922.

33. Zopf, W. Thielavia basicola Zopf. Genus novum Perisporiacearum. Sitz. Bot. Ver. Prov. Brandenb. 18: 101-105. 1876.

34. Zopf, W. Ueber die Wurzelbräune der Lupinen, eine neue Pilzkrankheit. Zeitschr. Pflanzenkrank. I: 72-76. 1891. 


\section{Explanation of Plates.}

Plate XXXVII.

Fig. 1. Violet plants infected with Thielaviopsis basicola (Berk.) Ferraris and Thielavia basicola Zopf.

Fig. 2. Part of section of infected violet root. p, perithecia of Thielavia basicola.

Fig. 3. Part of section of infected violet root showing sclerotial masses of hyphae and chlamydospores of Thielaviopsis basicola. Photographed by Mr. E. M. Stoddard.

Fig. 4. Part of section of infected violet root showing perithecia of Thielavia basicola.

Fig. 5. Part of section of infected pea root showing perithecia of Thielava basicola. Photographed by Mr. E. M. Stoddard.

Fig. 6. Part of section of infected tobacco root shorving perithecia of Thielavia basicola. Photographed by Mr. E. M. Stoddard.

\section{Plate XXXVIII}

Figs. 1-s.

Germination of ascospores of Thielavia basicola Zopf. Figs. 1 and 6 magnification $\times 1,000$; Figs. $2-5$ and $7-8$ mag. $x+50$.

Figs. 9 and 10. Hyphae of Thielavia basicola Zopf. x 600.

Figs. 11-22. Stages in the development of the perithecium of Thielavia basicola Zopf. Figs. 11-16, 18, 20-22, magnification $\times 1200$. Figs 17 and 19 mag. x 1,000.

Fig. 23. An ascus of Thielavia basicola Zopf with ascospores. $\mathrm{x} 1,200$. 
PLATE XYXVII.
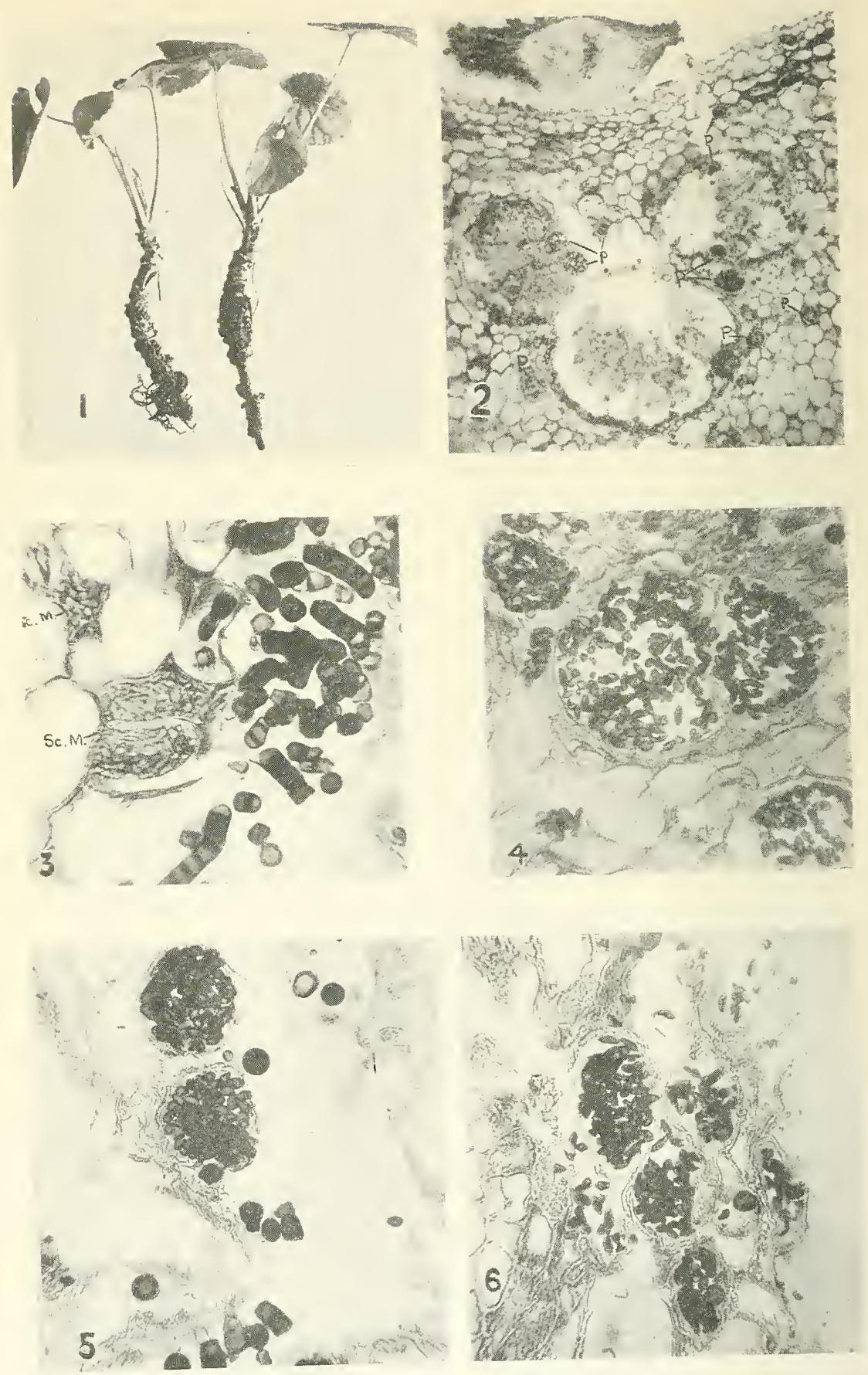
PLATE XXXVIII.
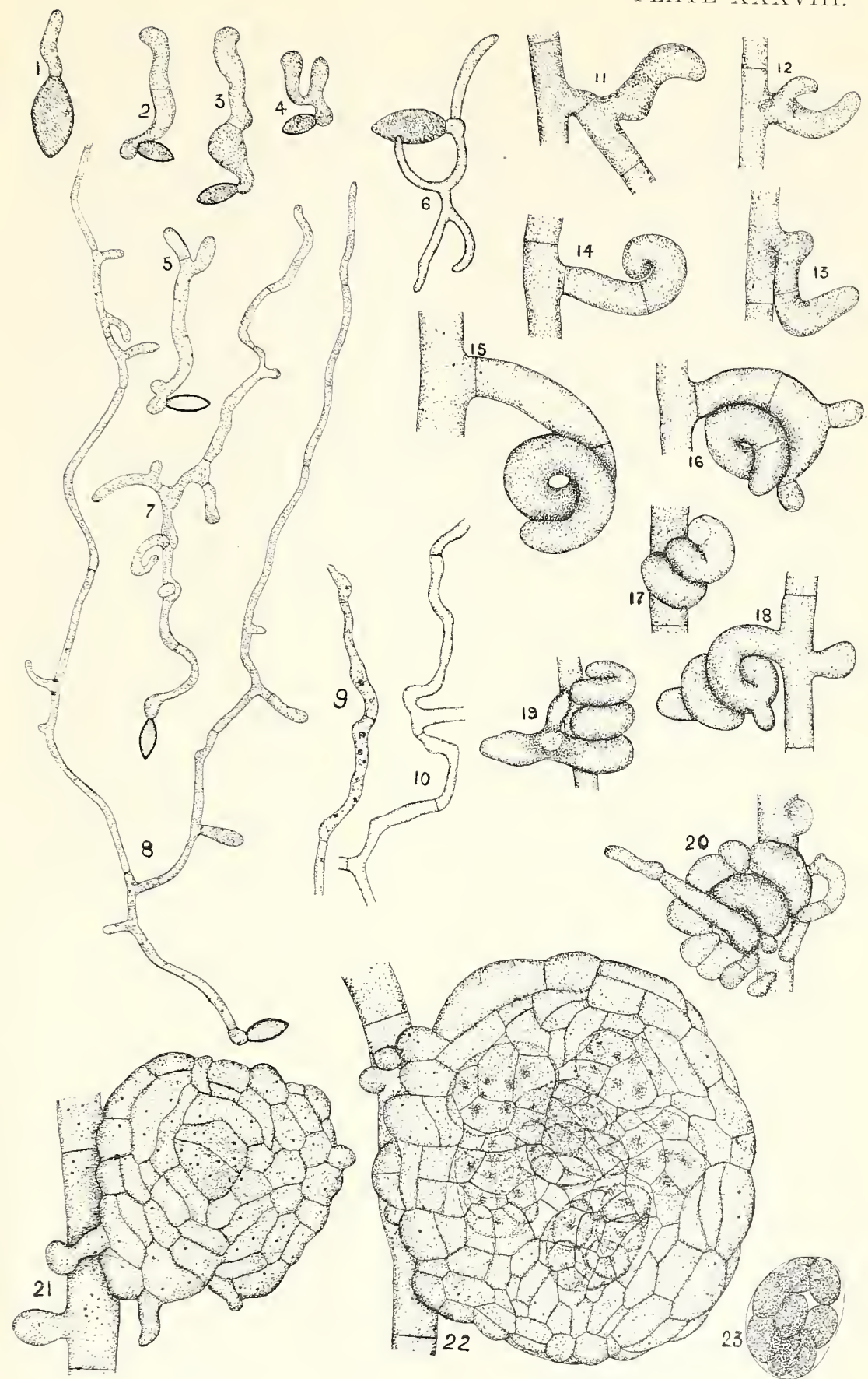


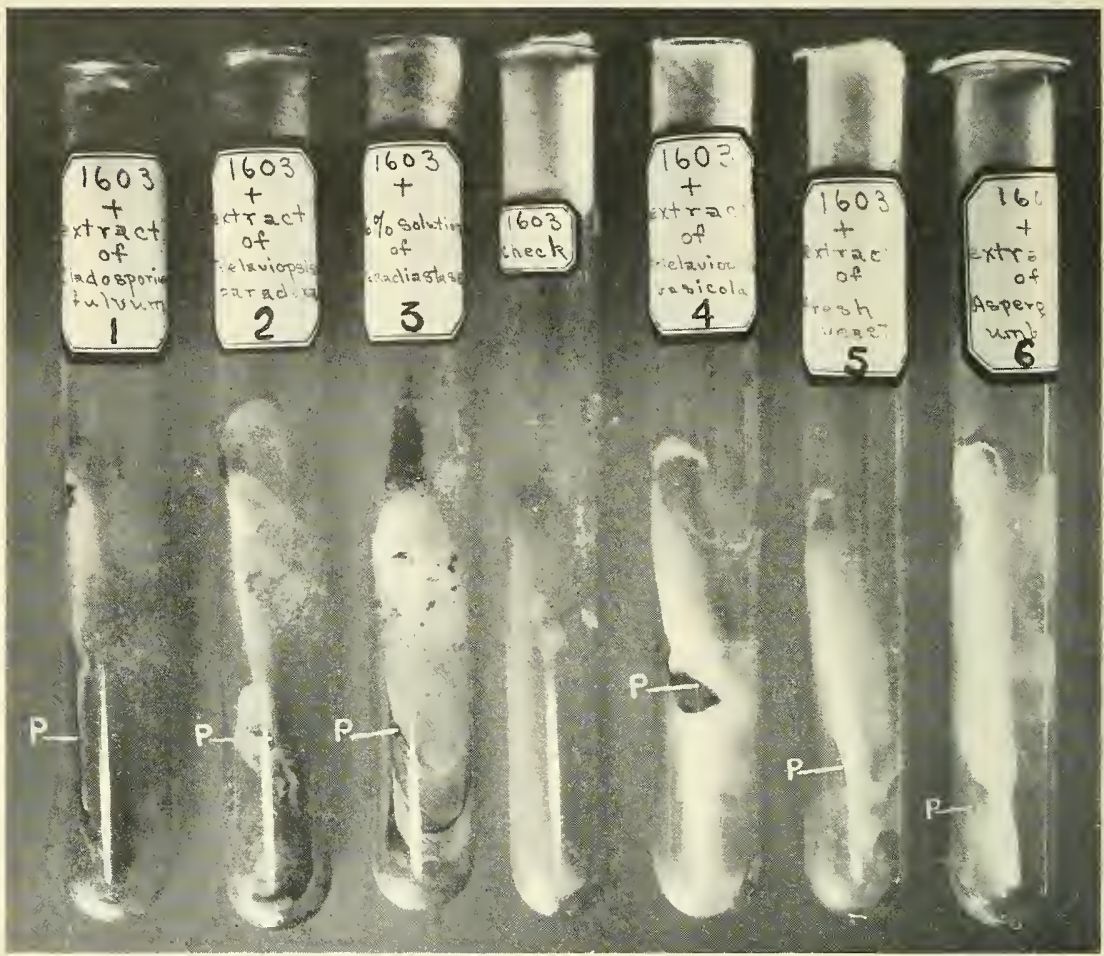

Cultures of 1603 on pea meal agar. P, perithecia.

No. 1. Addition of a few drops of extract from Cladosporium fulvum.

No. 2. Addition of a few drops of extract from Thielaviopsis paradoxa.

No. 3. Addition of a few drops of $6 \%$ water solution of Taka-diastase.

Check. Pea meal agar alone.

No. 4. Addition of a few drops of extract from Thielaviopsis basicola (Berk.) Ferraris.

No. 5. Addition of a few drops of extract from Saccharomyces Cerevisiae.

No. 6. Addition of a few drops of extract from Aspergillus umbrosus. Photographed by E. M. STODDARD.

$$
3.38 \cdot 91
$$




University of

Connecticut

Libraries

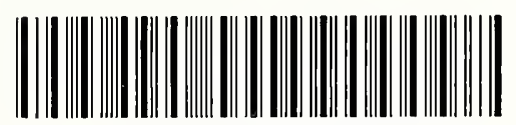

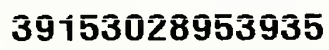




\section{(19)}

1. H. a)

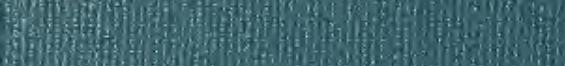

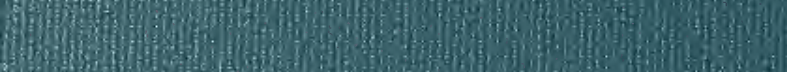
(2)

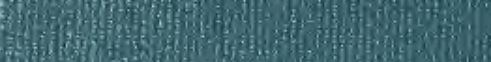

